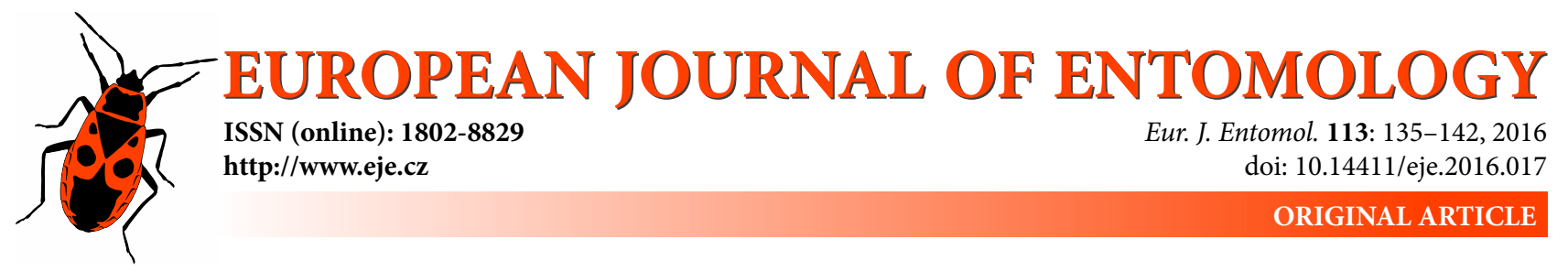

\title{
Effects of ultraviolet-C and microwave irradiation on the expression of heat shock protein genes in the maize weevil (Coleoptera: Curculionidae)
}

\author{
JATUPORN TUNGJITWITAYAKUL ${ }^{1}$, NUJIRA TATUN ${ }^{1}$, BoONGEUA VAJARASATHIRA ${ }^{2}$ and SHo SAKURAI ${ }^{3}$ \\ ${ }^{1}$ School of Science, University of Phayao, Phayao 56000, Thailand; e-mails: jatuporn.tu@up.ac.th, nujira.ta@up.ac.th \\ ${ }^{2}$ Department of Zoology, Faculty of Science, Kasetsart University, Bangkok 10900, Thailand; e-mail: fscibov@ku.ac.th \\ ${ }^{3}$ Creative Science Museum, Komatsunomori, Komatsu 923-8610, Japan; e-mail: ssakurai@staff.kanazawa-u.ac.jp
}

Key words. Coleoptera, Curculionidae, Sitophilus zeamais, UV-C, microwave, heat shock proteins, Hsp70, Hsc70, Hsp90

\begin{abstract}
The maize weevil, Sitophilus zeamais (Motschulsky), is a major pest of stored grain kernels. Irradiation is an established technique for controlling insects in stored grain and is a major stress factor affecting these insects. Since heat shock protein (hsp) genes respond to this stress, we proposed that hsps may be associated with irradiated stress tolerance in S. zeamais. The responses of the maize weevil to exposure to ultraviolet-C (UV-C) and microwave irradiation were assessed at four developmental stages: egg, larva, pupa and adult. The results revealed that exposure to UV-C $(254 \mathrm{~nm},<8 \mathrm{~h})$ did not affect the survival of the maize weevils; however, Szhsp70, Szhsc70 and Szhsp90 mRNA levels significantly increased during the first $1 \mathrm{~h}$ of UV-C exposure. The median lethal time $\left(\mathrm{LT}_{50}\right)$ of exposure to microwave irradiation indicated that the adult stage was more tolerant of microwave irradiation than the other developmental stages. Microwave irradiation enhanced the expression of the three hsps, but the intensity of up-regulation differed among the three genes, with Szhsp70 the most highly up-regulated. Our experiments revealed that UV-C and microwave irradiation influenced the expression profile of $h s p$ genes in $S$. zeamais. At the tissue level, the gene responses to UV-C and microwave irradiation varied greatly in different tissues.
\end{abstract}

\section{INTRODUCTION}

The maize weevil, Sitophilus zeamais (Motschulsky), is one of the most important insect pests of maize and other cereals during storage (Noomhorm et al., 2009; Vadivambal et al., 2010). The immature stages of this weevil develop inside the kernels, which results in a loss of weight and deterioration of the grain (Storey, 1987; Noomhorm et al., 2009). Methyl bromide and phosphine are commonly applied worldwide as effective methods to control infestations of storage pests. However, these have resulted in serious environmental damage and are a hazard to human health. Moreover, these pests are becoming increasingly more resistant to phosphine fumigation (Zhao et al., 2007).

Ultraviolet (UV) irradiation has been widely used to kill insects at various stages in their life cycles (Baden et al., 1996). The shortest wavelength radiation, UV-C (100-280 $\mathrm{nm}$ ), is the most active and has the greatest potential to induce biological damage (Pattison \& Davies, 2006). The efficacy of UV-C against some beetles and mite pests in stored products is well established (Calderon \& Navarro, 1971; Furaki et al., 2007; Lah et al., 2012), with sensitivities depending on the species and dose. This has led to a number of investigators considering the possibility of using UV-rays to control, or at least suppress, the development of various species of insects in stored products (Furaki \& Khan, 1993; Sharma \& Dwivedi, 1997).

The physiological processes of insects are also negatively affected by microwave irradiation (Webber et al., 1980). Microwave irradiation, with good penetrability, can kill pests both inside and outside grain kernels (Halverson et al., 1999) and damage DNA in cells (Lu et al., 2010). Exposure to microwave energy causes physical injuries in insects, which leads to a considerable reduction in their reproduction and survival. To date, a great deal of research has been conducted on the use of microwave irradiation to control pests in stored products (Vadivambal et al., 2008; Valizadegan et al., 2009; Lu et al., 2010).

Heat shock proteins (hsp) have a central role in the molecular mechanisms underlying the protection of living organisms from stress (Tammariello et al., 1999), as stressors induce rapid activation of $h s p$ genes and lead to an increase in hsps in stressed cells (Yu et al., 2012). In most organisms, hsp70 and hsp90 proteins are characterized by their high sensitivity to stressors. Hsp70 and hsp90 are expressed at low levels under normal physiological conditions and increase strongly in response to various stresses such as 
heat shock, cold shock, toxic substances, pathogen infection and radiation (Mahroof et al., 2003, 2005; Guedes et al., 2008; Chen et al., 2014). Hsc70 is constitutively expressed in non-stressed cells and only mildly induced by stress (Feder \& Hofmann, 1999).

UV and microwave irradiation is generally considered to be a common and significant stress affecting animals (Sang et al., 2012). The rice weevil, S. oryzae, is one of the most susceptible species to radiation (Cornwell et al., 1957). Since the maize weevil, S. zeamais, belongs to the same genus, it is assumed that similar hsps are involved in the molecular response of $S$. zeamais to UV-C and microwave irradiation. Numerous studies report that irradiation induces the expression of the $h s p 70$ gene in mammalian cells (Calini et al., 2003), hsp70 in chick embryos (Shallom et al., 2002) and synthesis of hsp25 proteins in mouse cells (Lee et al., 2006). There are, however, little data on the effects of irradiation on insect hsp genes.

In this study, we recorded the mortality of $S$. zeamais at four developmental stages, egg, larva, pupa and adult, after exposure to UV-C and microwave irradiation. We also determined the response of maize weevil to UV-C and microwave irradiation in terms of changes in expression of three Szhsp genes, $h s p 70, h s c 70$ and $h s p 90$, at individual and tissue levels.

\section{MATERIAL AND METHODS}

\section{Test insects}

Stock cultures of $S$. zeamais were established and maintained in the laboratory for $1 \mathrm{yr}$ in the dark at $28 \pm 1{ }^{\circ} \mathrm{C}$ and a $65 \pm 5 \%$ relative humidity. Weevils were reared on heat-sterilized brown rice grains in a wide-mouthed glass jar covered with muslin cloth held in position by rubber bands. To ensure their proper development, insects were kept under moderately crowded conditions. The life cycle of $S$. zeamais at $28^{\circ} \mathrm{C}$ was as follows: egg stage, 3 days; larval stage in which the fourth instar is the last larval instar, approximately 22 days; pupal stage, 7 days; adult stage, approximately 6 months. Three day old eggs, 21 day old larvae, 3 day old pupae and 10 day old adults were used in all experiments. The 21 day old larvae became prepupae on day 22 and pupated the following day.

\section{UV-C irradiation}

The irradiation source was a 17 -watt UV germicidal lamp (TUV F17T8, Philips, Amsterdam, The Netherlands) measuring $58 \times 2.5 \mathrm{~cm}$, emitting irradiation at a wavelength of $254 \mathrm{~nm}$. The lamp was fixed to the ceiling of a test chamber $(90 \times 60 \times 55 \mathrm{~cm})$. The stage on which the insects were exposed to irradiation was 5 $\mathrm{cm}$ from the surface of the UV lamp. Three replicates of 20 eggs, larvae, pupae or adults were placed in $7 \times 10 \mathrm{~cm}$ plastic zip top bags. The bags containing insects at the four different stages were each exposed to UV-C irradiation for $0,15,30,45$ or $60 \mathrm{~min}$. Bioassays were conducted at $28 \pm 1^{\circ} \mathrm{C}$.

\section{Microwave treatment}

For the microwave treatment, insect specimens were irradiated with microwave energy using a ME711K microwave oven (Samsung, Suwon, S. Korea). The effective length, width and height of the oven were $34.3,48.9$ and $27.5 \mathrm{~cm}$, respectively. The power output of the generator was adjustable, from 0 to $800 \mathrm{~W}$. To determine the median lethal time $\left(\mathrm{LT}_{50}\right)$ for the microwave treatments, 3 replicates of 20 rice grains containing either eggs, larvae, pupae or adults were placed in $7 \times 10 \mathrm{~cm}$ plastic zip top bags (Lu et al., 2010, 2011). The bags containing the different insect specimens were treated with microwave irradiation at 0,300 , $450,600,700$ or $800 \mathrm{~W}$ for 5 - to 100 -s. After each treatment, the weevils were removed from the bags and kept for examination. Adults were kept at the standard rearing conditions, and mortality was recorded $1 \mathrm{~d}$ following the treatment. The treated insects were transferred onto a sheet of paper and rubbed gently with a paintbrush number 0 . Adults were declared dead if they did not respond to the rubbing. Eggs, larvae and pupae which were inside the rice grains were kept for 45,25 and $15 \mathrm{~d}$ following the treatment, respectively, and the number of adults that emerged was record, from which the mortality rate was calculated.

\section{Time-dependent expression of Szhsps}

Because UV-C irradiation did not affect the survival of maize weevil adults, we determined its effect on the expression of $S z h$ sps. Rice grains were opened under a stereo microscope to remove the eggs, larvae and pupae, which were placed in zip top bags. Each stage was irradiated for 0, 15, 30, 45 and 60 min. Since the $\mathrm{LT}_{50}$ after microwave irradiation differed for the four developmental stages, rice grains containing eggs, larvae, pupae and adults $(\mathrm{n}=20)$ were placed in separate zip top bags and exposed to microwave power at $300 \mathrm{~W}$ for $5,10,15,20$ and $25 \mathrm{~s}$ for eggs, at 10, 15, 20, 25 and $30 \mathrm{~s}$ for larvae and pupae, and at 20, $40,60,80$ and $100 \mathrm{~s}$ for adults. For each stage this was repeated three times. Whole bodies of insect specimens were subjected to RNA extraction immediately following UV-C and microwave irradiation.

\section{RNA isolation and cDNA synthesis}

Immediately after treatment, total RNA was isolated from whole bodies of insect specimens or adult tissues using Ribo$\mathrm{Zol}^{\mathrm{TM}}$ RNA extraction reagent (Amresco, OH, USA) following the supplier's instructions. Total RNA was treated with RNasefree DNaseI (Thermo Scientific, MA, USA) and then subjected to reverse transcription (RT) using oligodT and M-MuLV reverse transcriptase (Sibenzyme, Novosibirsk, Russia).

\section{Tissue distribution of Szhsps}

Adults were placed in zip top bags and irradiated under UV-C for $60 \mathrm{~min}$ or microwave power at $300 \mathrm{~W}$ for $60 \mathrm{~s}$. Immediately after treatment, 30 adults were dissected in Ringer's solution (128 $\mathrm{mM} \mathrm{NaCl}, 18 \mathrm{mM} \mathrm{CaCl}_{2}, 1.3 \mathrm{mM} \mathrm{KCl}$ and $2.3 \mathrm{mM} \mathrm{NaHCO}_{3}$ ) and their ovaries, testes, gut, fat bodies, subesophageal ganglion and Malpighian tubules removed, which were then immediately individually homogenized in RiboZol ${ }^{\mathrm{TM}}$ RNA extraction reagent (Amresco, OH, USA) to obtain the total RNA.

\section{Quantification of gene expression}

Gene expression was assessed using quantitative real-time PCR (qPCR). qPCR was done using a $20 \mu \mathrm{l}$ total reaction volume including $10 \mu 12 \times$ SensiFAST SYBR No-ROX Mix (Bioline, MA, USA), $0.8 \mu 110 \mu \mathrm{M}$ gene-specific primers for $S z h s p 70$, Szhsp 90 and Szhsc70, $2 \mu 1$ cDNA template (generated from 200 ng total RNA) and $6.4 \mu \mathrm{l}$ DEPC-treated water. Reaction mixtures without the cDNA template were used as a negative control. There were three technical replicates of each sample. The primers used for Szhsp 70 were 5'-AGCGGAGGAAAACCAAAATTA-3' and 5'-CAGCTTGCCTCTGGGAATC-3', with a 184 bp product. The primers used for Szhsp90 were 5'-CGAAGCACAACGATGATGAA-3' and 5'-TTGGGAATGTTTCTTGACGA-3', with a 182 bp product and the primers used for $S z h s c 70$ were 5'-TGCCGTACAAGCTGATATGAAA-3' and 5'-GACGTTGTGAATCATTAAAATAGGCT-3', with a 224 bp product. The elongation factor $1-\alpha$ gene (EF-1) of $S$. zeamais (Gen- 
bank: AY131129.1) served as a reference gene. The primers for $S z E F-1$ were 5'-AATCTCAGGATGGCATGGAG-3' and 5'-CTGGAGTGGAAGACGGAGAG-3', with a 178 bp product. PCR reactions were carried out on a CFX $96^{\mathrm{TM}}$ real-time system (Bio-Rad, CA, USA) according to the operation manual. The PCR parameters for the melting curve were as follows: 2 min at $95^{\circ} \mathrm{C} ; 40$ cycles of $5 \mathrm{~s}$ at $95^{\circ} \mathrm{C}, 10 \mathrm{~s}$ at $60^{\circ} \mathrm{C}$ and $15 \mathrm{~s}$ at $72^{\circ} \mathrm{C}$; then $10 \mathrm{~s}$ at $95^{\circ} \mathrm{C}, 10 \mathrm{~s}$ at $70^{\circ} \mathrm{C}$, and $20 \mathrm{~s}$ at $96^{\circ} \mathrm{C}$ (gradient rising to $96^{\circ} \mathrm{C}$, with an interval of $0.2^{\circ} \mathrm{C}$ ). The analysis of the qPCR results was performed using the $2^{-\Delta \Delta \mathrm{Ct}}$ method (Livak \& Schmittgen, 2001). All samples were normalized with respect to the reference gene to obtain the $\Delta \mathrm{Ct}$ value $\left(\mathrm{Ct}_{\text {target gene }}-\mathrm{Ct}_{\mathrm{EF}-1}\right)$ and then to the calibrator value (untreated control) to obtain the $\Delta \Delta \mathrm{Ct}$ value ( $\Delta \mathrm{Ct}_{\text {target }}$ $\left.\Delta \mathrm{Ct}_{\text {calibrator }}\right)$. The final relative expression was calculated using the formula $\mathrm{F}=2^{-\Delta \Delta \mathrm{Ct}}$ (Chen et al., 2014).

The responses of Szhsp70, Szhsp90 and Szhsc70 to UV-C or microwave irradiation at different developmental stages were analyzed by normalizing the amount of each $S z h s p$ mRNA to $S z E F-1$, after which the normalized value was divided by the normalized value of $S z h s p$ in the control for each developmental stage; the expression of the control was thus set to 1. Expression of the three Szhsps in adult tissues after UV-C (for $60 \mathrm{~min}$ ) or microwave irradiation (for $60 \mathrm{~s}$ ) was also analyzed by normalizing the amount of each $S z h s p$ mRNA to that of $S z E F-1$ in each tissue, after which the normalized value of each $S z h s p$ was then divided by the normalized value of $S z h s p$ in the control. Thus, the normalized expression level of the control was set to 1 in individual tissues.

\section{Data analysis}

Mortality data were processed using Probit analysis and SPSS program version 11.5. The data obtained from the different time points were determined using a one-way analysis of variance (ANOVA; SPSS program version 11.5), followed by a LSD multiple range test. Significant differences in tissues between the control (no stress) and treatment groups (UV-C or microwave irradiation) were identified by an independent-sample $t$ test (SPSS program version 11.5). The significance level was set at 0.05 $(P<0.05)$.

\section{RESULTS}

\section{Effects of UV-C and microwave irradiation on mortality}

The effect of UV-C irradiation on S. zeamais was first examined in the adults. All adults survived exposure to $\mathrm{UV}-\mathrm{C}$ irradiation for 1 to $8 \mathrm{~h}$ (data not shown), indicating that UV-C had no effect on the survival of S. zeamais. On the other hand, microwave irradiation had a lethal effect on $S$. zeamais. The $\mathrm{LT}_{50}$ of $S$. zeamais after exposure to a series of different microwave powers over various exposure times is shown in Table 1 . The $\mathrm{LT}_{50}$ values at each power differed for the four developmental stages. The results indicate that adults were the most tolerant of microwave irradiation, followed by pupae, larvae and then eggs. The mortality of irradiated weevils was directly proportional to the exposure times.

\section{Effects of UV-C exposure time on Szhsps expression}

The time course of Szhsp expression after UV-C irradiation for the four developmental stages is shown in Fig. 1. A time-dependent expression pattern was clearly observed for Szhsp70 in the eggs, larvae and adults, but not in the
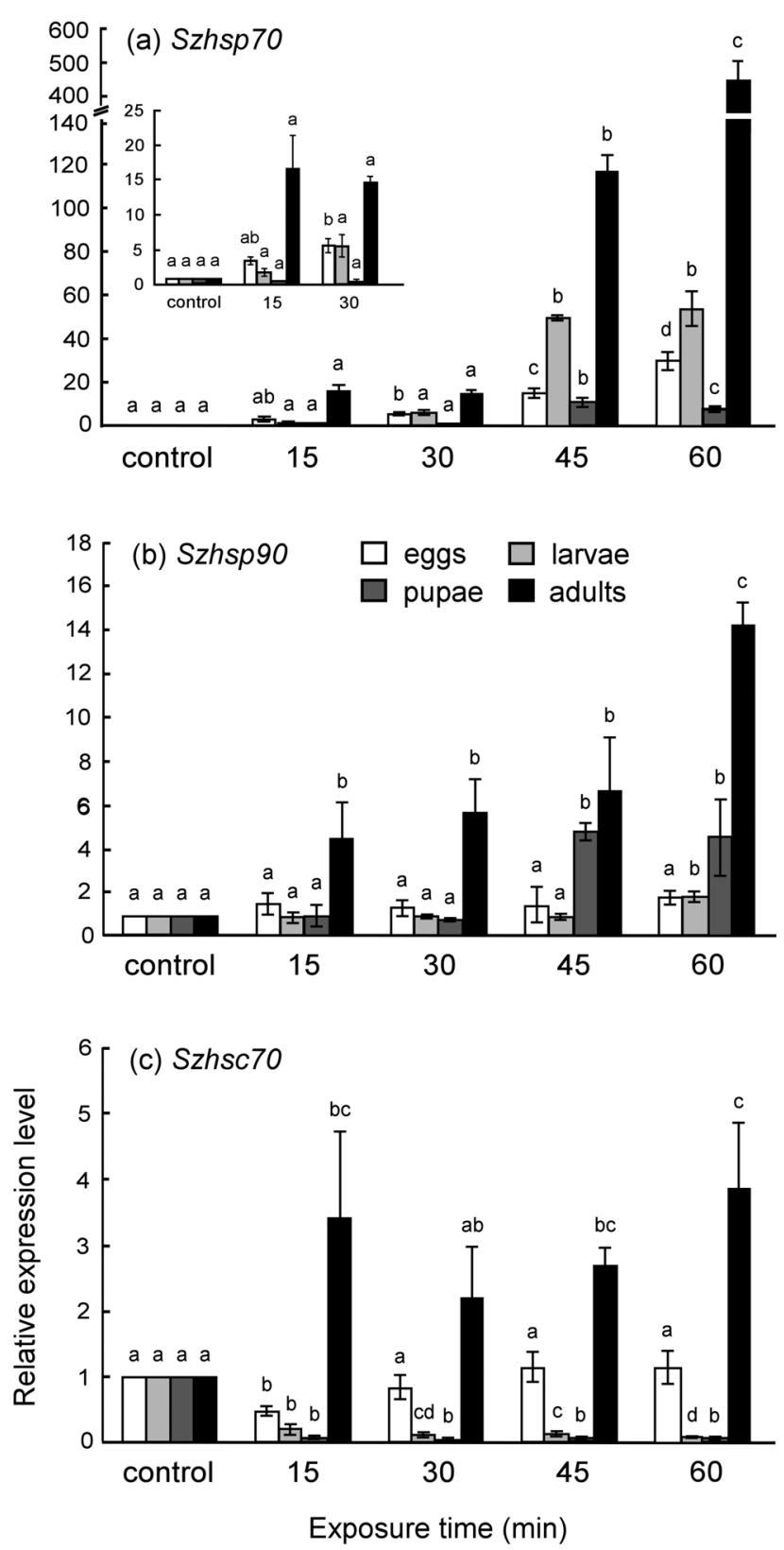

Fig. 1. The responses of three Szhsps in different developmental stages of $S$. zeamais to UV-C irradiation. Bars indicate the means of three independent biological replicates and include the standard deviations (S.D). Different letters above the bars indicate significant differences compared with the other exposure times $(P<$ $0.05)$.

pupae. After UV-C exposure, the expression of Szhsp70 in the eggs, larvae and adults increased dramatically and peaked at $60 \mathrm{~min}$. Szhsp 70 in the pupae increased for 45

Table 1. Median lethal time $\left(\mathrm{LT}_{50}\right)$ of the maize weevil, S. zeamais, after microwave irradiation.

\begin{tabular}{lcccc}
\hline \multirow{2}{*}{ Power $(\mathrm{W})$} & \multicolumn{4}{c}{$\mathrm{LT}_{50}(\mathrm{~s})$} \\
\cline { 2 - 5 } & egg & larva & pupa & adult \\
\hline 300 & $12.35 \pm 2.84$ & $28.49 \pm 3.50$ & $27.74 \pm 2.83$ & $82.57 \pm 9.47$ \\
450 & $*$ & $5.74 \pm 1.29$ & $13.46 \pm 1.11$ & $50.52 \pm 3.85$ \\
600 & $*$ & $*$ & $10.03 \pm 1.02$ & $37.71 \pm 1.15$ \\
700 & $*$ & $*$ & $6.81 \pm 2.85$ & $24.31 \pm 2.34$ \\
800 & $*$ & $*$ & $4.45 \pm 1.13$ & $21.16 \pm 1.90$ \\
\hline
\end{tabular}

* Asterisk indicates no insects survived microwave irradiation. 
min and then decreased for $60 \mathrm{~min}$. Compared with the other three stages, the response of this gene in the pupae was limited. These results indicate that the intensity of the exposure-time response of Szhsp70 varies depending on the developmental stage. The greatest increase was recorded in adults after UV-C irradiation for $60 \mathrm{~min}$, which was 430-fold higher than that recorded in the control (Fig. 1a), followed by 54-, 30- and 8-fold increases in the larvae, eggs and pupae, respectively.

UV-C irradiation enhanced Szhsp90 expression in the larvae, pupae and adults, but not in eggs. It was noteworthy that the intensity of the up-regulation was much lower than that of $S z h s p 70$. The increased level of $S z h s p 90$ expression in adults was highest, reaching a 14-fold increase at $60 \mathrm{~min}$ (Fig. 1b), followed by 5- and 1.9-fold increases in pupae and larvae, respectively.

Szhsc70 showed a different pattern of expression from that of Szhsp70 and Szhsp90. Szhsc70 expression in eggs was not altered by UV-C irradiation but was downregulated in the larvae and pupae after UV-C irradiation for 15 to $60 \mathrm{~min}$ (Fig. 1c). The Szhsc70 expression pattern in the adults differed from that in the eggs, larvae and pupae. The gene expression in irradiated adults increased at $15 \mathrm{~min}$, decreased slightly at $30 \mathrm{~min}$, and exhibited significant upregulation at 45 and $60 \mathrm{~min}$. Szhsc70 showed the highest expression level (4-fold) at $60 \mathrm{~min}$.

\section{Effect of exposure to microwave irradiation on Szhsps expression}

Since the $\mathrm{LT}_{50}$ values of the four developmental stages after microwave irradiation at $300 \mathrm{~W}$ differed, the weevils were irradiated for longer than the $\mathrm{LT}_{50}$ values of each stage. Szhsp70 expression was significantly increased at 15 $\mathrm{s}$ in the eggs and pupae and at $20 \mathrm{~s}$ in the larvae and adults. Szhsp70 expression levels in the eggs peaked at $20 \mathrm{~s}$ and decreased at $25 \mathrm{~s}$ of exposure (Fig. 2a). Microwave irradiation enhanced $S z h s p 70$ expression in the larvae, peaking at $20 \mathrm{~s}$, and was then down-regulated at $30 \mathrm{~s}$ (Fig. 2b). In the pupae, Szhsp 70 expression was high at $15 \mathrm{~s}$, decreased at 20 and $25 \mathrm{~s}$, and then increased slightly at $30 \mathrm{~s}$ (Fig. 2c). The Szhsp70 expression level in the adults was relatively high at 20 to $40 \mathrm{~s}$ and peaked at $60 \mathrm{~s}$. After 80 to $100 \mathrm{~s}$ of exposure, Szhsp70 expression levels decreased and remained at the basal level (Fig. 2d). The maximal intensities of the gene response varied among the developmental stages: there was a 59-fold increase in adults and 44-, 14-, and 5.8-fold increases in larvae, pupae and eggs, respectively.

Szhsp90 expression in the eggs, larvae and adults exhibited a similar pattern to $S z h s p 70$ expression but showed little response to microwave irradiation. The expression levels in eggs, larvae and adults increased by only 1.5- to 2.8-fold relative to the control (Figs $2 \mathrm{a}$, b and d). In contrast to the other three stages, Szhsp90 expression in the pupae was significantly decreased after microwave treatment (Fig. 2c).

Szhsc70 exhibited the opposite expression pattern to that of Szhsp70 and Szhsp90, as it was down-regulated in the eggs, larvae and pupae after microwave irradiation. How-
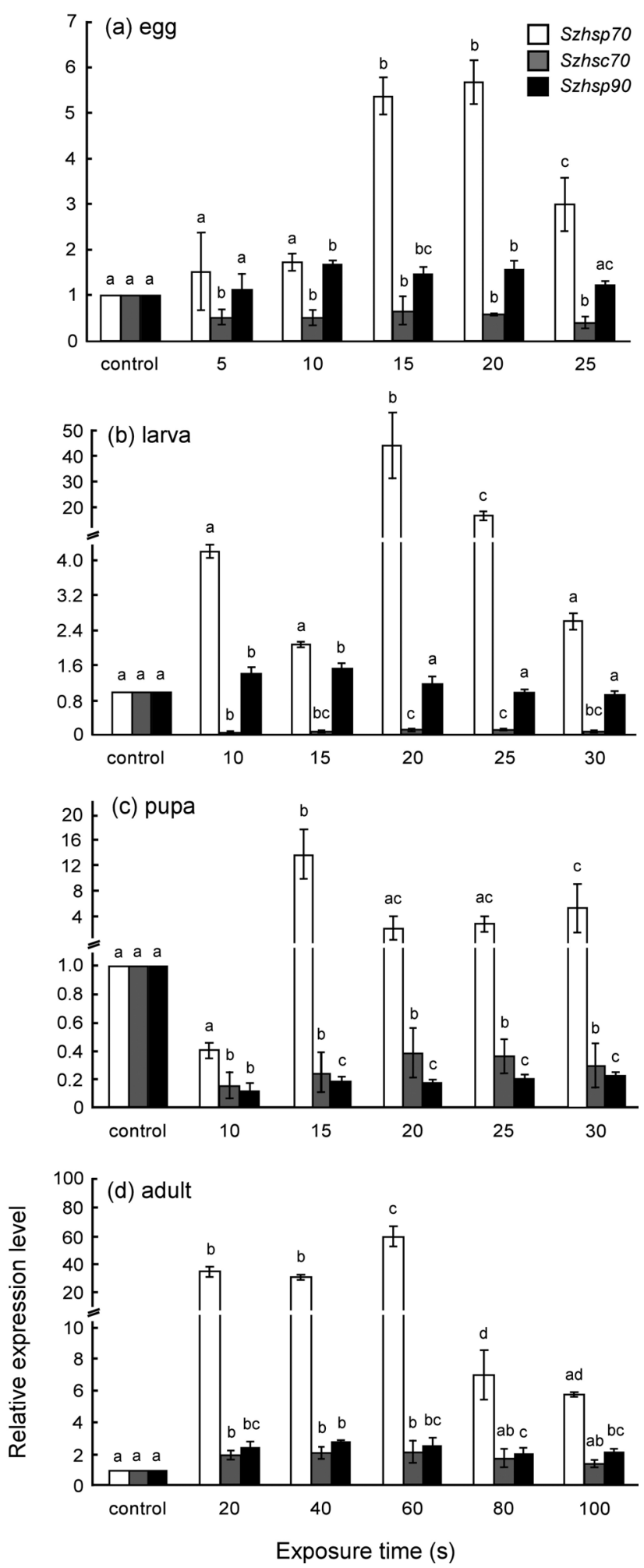

Fig. 2. Responses of three Szhsps in different developmental stages of $S$. zeamais to microwave irradiation. Bars indicate the means of three independent biological replicates and include the standard deviations (S.D). Different letters above the bars indicate significant differences compared with the other exposure times ( $P$ $<0.05)$.

ever, there was a slightly increased expression in the adults, with a maximum level at $60 \mathrm{~s}$ after exposure but with only a 2 -fold increase relative to the control. 

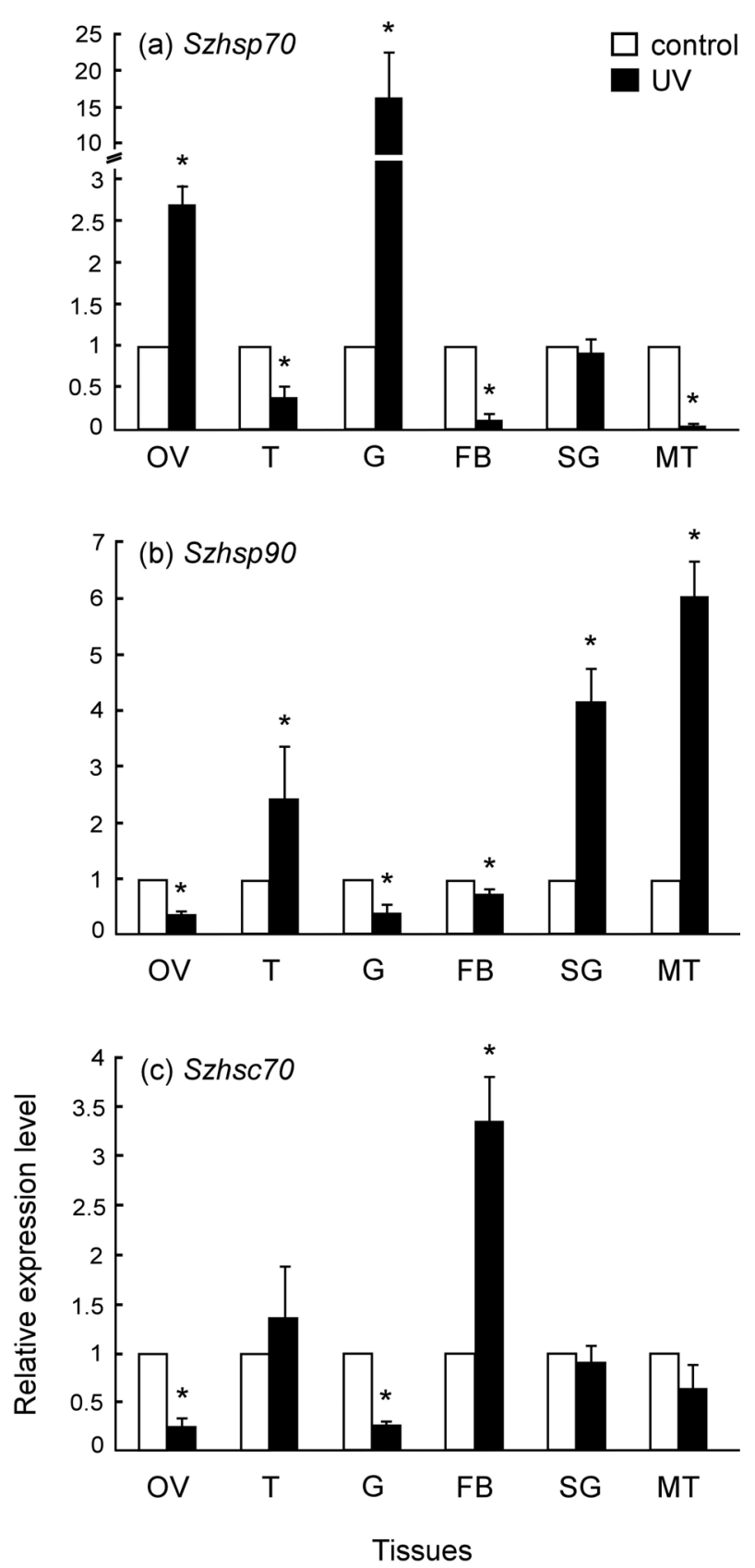

Fig. 3. Expression of the three Szhsps in adult tissues after exposure to UV-C irradiation for 60 min. OV - ovary; T - testis; G - gut; FB - fat body; SG - subesophageal ganglion; MT - Malpighian tubule. Asterisks above the bars within each tissue indicate significant differences $(P<0.05)$ between the treatment and control groups.

\section{Tissue-specific gene responses to UV-C and microwave irradiation}

Szhsps responded to UV-C and microwave irradiation in a tissue-specific manner (Figs 3 and 4). After UV-C irradiation for $60 \mathrm{~min}$, Szhsp 70 was up-regulated in the ovaries and gut by 2.7 - and 15.9 -fold relative to the control, respectively (Fig. 3a). UV-C enhanced Szhsp 90 expression in the testes, subesophageal ganglion and Malpighian tubules (Fig. 3b). In contrast to $S z h s p 70$ and Szhsp90, UV-C suppressed $S z h s c 70$ expression in the ovaries and gut, while its expression in the testes, subesophageal ganglion and Mal-
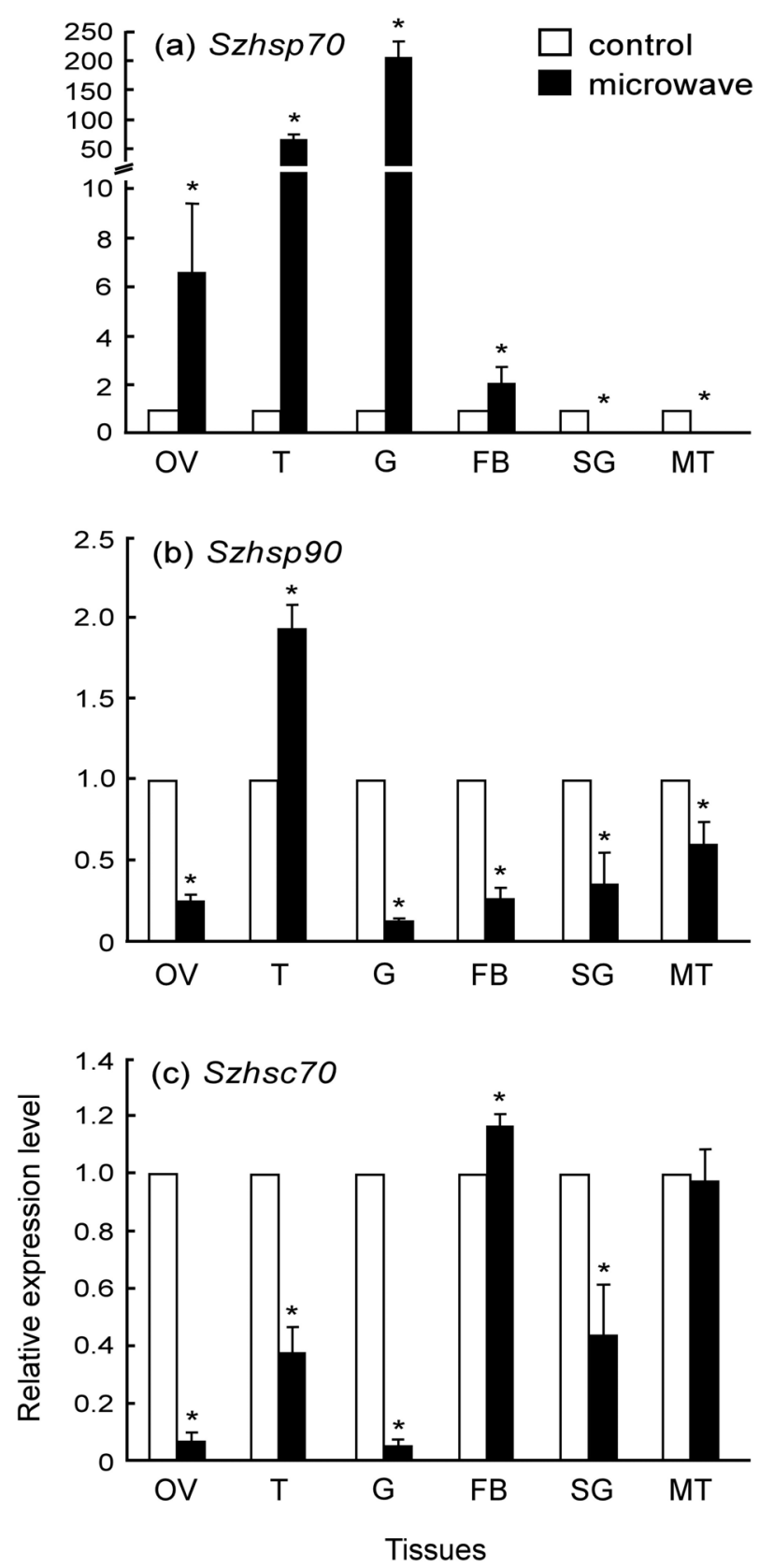

Fig. 4. Expression of the three Szhsps in adult tissues after exposure to microwave irradiation for $60 \mathrm{~s}$. OV - ovary; $\mathrm{T}$ - testis; G - gut; FB - fat body; SG - subesophageal ganglion; MT - Malpighian tubule. Asterisks above the bars within each tissue indicate significant differences $(P<0.05)$ between the treatment and control groups.

pighian tubules was not affected. Up-regulation of $\operatorname{Szhsc} 70$ by UV-C was recorded only in the fat bodies (Fig. 3c).

The responses of Szhsps to microwave irradiation at 300 $\mathrm{W}$ for $60 \mathrm{~s}$ also varied among the tissues. Microwave irradiation up-regulated $S z h s p 70$ in the gut, testes, ovaries and fat bodies by 198-, 59-, 6.6- and 2-fold compared with the control, respectively (Fig. 4a). Microwave irradiation increased the expression of Szhsc70 only in the fat bodies by $\sim 1.2$-fold compared with the control (Fig. 4c), while expression of Szhsp 90 in testes was 1.9-fold higher than in the control (Fig. 4b). Szhsps was markedly down-regulated in other tissues, except for Szhsc70 in the Malpighian 
tubules, which did not respond to microwave irradiation (Fig. 4c).

\section{DISCUSSION}

\section{Effects of UV-C and microwave irradiation on $S$. zeamais survival}

S. zeamais adults exposed to UV-C for 1 to $8 \mathrm{~h}$ showed no lethal effects. Since UV-C has a limited ability to penetrate surfaces, its effects are limited to the body surface (Ghanem \& Shamma, 2007). In addition, cuticular thickness and protective pigments in the adult epithelium can withstand UV and are important for limiting penetration into the body (Buck \& Callaghan, 1999; McCloud \& Berenbaum, 1999). This result is consistent with those for the red flour beetle, Tribolium castaneum (Herbst) (Sang et al., 2012), and the potato aphid, Macrosiphum euphorbiae (Thomas) (Nguyen et al., 2009), in which UV exposure had no lethal effects.

In contrast to UV-C, microwave irradiation was lethal for the maize weevil. The mechanisms involved in the lethal action of microwave irradiation could be due to the high oscillation frequency of water molecules in the bodies of the insects. Microwave heating is based on the transformation of alternating electromagnetic field energy into thermal energy by affecting the polar molecules of a material, and hence it can kill the insects at lower temperatures ( $\mathrm{Lu}$ et al., 2010). It was clear that increasing the microwave irradiation exposure time caused a significant increase in the mortality of $S$. zeamais. This suggests that microwave stress had a greater effect than that of UV-C stress. The $\mathrm{LT}_{50}$ of $S$. zeamais after microwave irradiation varied according to the developmental stage. Eggs were the most susceptible, followed by larvae, pupae and adults, in that order. Other studies also show that the egg stage of insects are more susceptible to irradiation than the other stages (Tilton \& Brower, 1983; Hasan \& Khan, 1998; Zhao et al., 2007; Vadivambal et al., 2010). Embryonic cells divide and grow more rapidly than other cells at later stages and this makes them more susceptible to damage from irradiation (Azizoglu et al., 2011). Exposure of adult S. zeamais to different microwave irradiances revealed a higher $\mathrm{LT}_{50}$ in adults, indicating that the adult stage was the more tolerant of irradiation than the early life stages.

\section{Expression of three Szhsp genes after UV-C and microwave irradiation}

The apparent lack of an effect on the survival of adult $S$. zeamais does not indicate that UV-C had no deleterious effects on the weevils. UV-C irradiation at $254 \mathrm{~nm}$ has a higher penetrative capacity than that of other UVs, and the response of Szhsp to UV-C was unique among the three genes evaluated. The speed of the response was substantially different depending on the developmental stage. Szhsp70 and Szhsp90, but not Szhsc70, were upregulated after UV-C irradiation. Szhsp70 and Szhsp 90 in adults showed the highest expression levels after the same exposure time, but the increase in expression of Szhsp70 was much higher than that of Szhsp90. This characteristic response of $h s p 70$ seems to be a common feature, as this is also reported for T. castaneum (Sang et al., 2012), in which $h s p 70$ is the most highly up-regulated. UV-C strongly suppressed $S z h s c 70$ expression in the eggs, larvae and pupae, but significantly induced Szhsc70 expression levels in the adults. However, the increase in $S z h s c 70$ expression in the adults was much lower than that of Szhsp70 and Szhsp90. These results indicated that UV-C may induce $S z h s p 70$ and Szhsp90 expression to protect the weevil from UV-C stress.

Similar to the $h s p$ gene responses to UV-C irradiation, the $S z h s p$ response to microwave stress was not uniform for the three genes examined. The timing of the gene responses and the increases in intensity depended on the developmental stage. Szhsp70 was up-regulated promptly in four developmental stages, while Szhsp 90 was up-regulated in the eggs, larvae and adults. In contrast, Szhsc70 was down-regulated in the eggs, larvae and pupae. It is reported that microwave irradiation induces an obvious thermal effect (Lu et al., 2010), hence increased temperature may be involved in the up-regulation of Szhsp70 and Szhsp 90 expression levels. This characteristic response of $h s p 70$ seems to be a common feature as it is reported in chick embryos (Shallom et al., 2002) and human neuroblastoma SH-SY5Y cells (Calabrò et al., 2012), in which microwave irradiation is able to induce a thermal effect and activate hsp70.

The temperature used to induce maximal hsp expression provides an important clue for our understanding of the limits of temperature tolerance (Huang \& Kang, 2007). In $S$. zeamais, expression of the Szhsp genes after microwave irradiation increased significantly depending on the exposure time but decreased at $\mathrm{LT}_{50}$. Exposure times over the $\mathrm{LT}_{50}$ resulted in a decline in the survival of all stages, which was consistent with decreased expression of Szhsps. This indicates that the ability of Szhsps to act as molecular chaperones might limit their mitigation of the damage caused by high temperatures at $\mathrm{LT}_{50}$ and above.

In this study, after UV-C irradiation, three Szhsps showed a tissue-specific expression pattern. Szhsp70 was expressed only in the ovaries and gut. On the other hand, after microwave irradiation, $S z h s p 70$ was up-regulated in the ovaries, testes and gut. It was noteworthy that $S z h s p 70$ in the gut showed the highest expression level after UV-C and microwave irradiation, and it is also reported that the activation of $S z h s p 70$ gene expression in gut increases after heat and cold treatment (Tungjitwitayakul et al., 2015). Similar to Apis cerana cerana (Fabricius) after UV irradiation, $h s p 22.6$ is detected at higher levels in the midgut than in other tissues tested (Zhang et al., 2014). After UV-C irradiation, the $S z h s p 90$ expression level was increased in the testes, subesophageal ganglion and Malpighian tubules, but only in the testes after microwave irradiation. In contrast to Szhsp70 and Szhsp90, Szhsc70 was up-regulated only in the fat bodies after UV-C and microwave irradiation, indicating that the three Szhsps were uniquely expressed in the different tissues in response to different stressors.

In conclusion, our study shows the responses of three heat shock protein genes in the $S$. zeamais to UV-C and microwave irradiation. An increase in Szhsp70 and Szhsp90 
expression may in turn protect the maize weevils from irradiation damage in a dose-dependent manner. However, the detailed mechanisms of how Szhsp 70 and Szhsp 90 are involved in the protection pathway need to be further examined using other techniques such as RNA interference.

ACKNOWLEDGEMENTS. We greatly appreciate Postharvest and Processing Research and Development Office, Department of Agriculture, Ministry for Agricultural and Cooperatives, Thailand for providing the $S$. zeamais culture. This work was supported by the Thailand Research Fund to J.T. (grant no. MRG5580017). We are grateful to the Thalasemia unit of the University of Phayao for providing laboratory facilities.

\section{REFERENCES}

Azizoglu U., Yilmaz S., Karabörklü S. \& Ayvaz A. 2011: Ovicidal activity of microwave and UV radiations on Mediterranean flour moth Ephestia kuehniella Zeller, 1879 (Lepidoptera: Pyralidae). - Tükr. Entomol. Derg. 35: 437-446.

Baden H.P., Kollias N., Anderson R.R., Hopkins T. \& RafFery L. 1996: Drosophila melanogaster larvae detect low doses of UVC radiation as manifested by a writhing response. - Arch. Insect Biochem. Physiol. 32: 187-196.

Buck N. \& Callaghan T.V. 1999: The direct and indirect effects of enhanced UV-B on the moth caterpillar Epirrita autumnata. - Ecol. Bull. 47: 68-76.

Calabrò E., Condello S., Currò M., Ferlazzo N., Caccamo D., MAgAzÙ S. \& IENTILE R. 2012: Modulation of heat shock protein response in SH-SY5Y by mobile phone microwaves. World J. Biol. Chem. 26: 34-40.

Calderon M. \& Navarro S. 1971: Effects of ultra-violet irradiation on the eggs of Ephestia cautella (Wlk.) (Lepidoptera: Phycitidae). - J. Stor. Prod. Res. 7: 309-311.

Calini V., Urani C. \& Camatini M. 2003: Overexpression of HSP70 is induced by ionizing radiation in $\mathrm{C} 3 \mathrm{H} 10 \mathrm{~T} 1 / 2$ cells and protects from DNA damage. - Toxicol. In Vitro 17: 561566.

Chen H., Xu X.L., Li Y.P. \& Wu J.X. 2014: Characterization of heat shock protein 90,70 and their transcriptional expression patterns on high temperature in adult of Grapholita molesta (Busck). - Insect Sci. 21: 439-448.

Cornwell P.B., Crook L.J. \& Bull J.O. 1957: Lethal and sterilizing effects of gamma radiation on insects infesting cereal commodities. - Nature 179: 670-672.

Feder M.E. \& Hofmann G.E. 1999: Heat-shock proteins, molecular chaperones, and the stress response: evolutionary and ecological physiology. - Annu. Rev. Physiol. 61: 243-282.

FURAKI S.I. \& KHAN A.R. 1993: Potency of UV-irradiation on $C$. cautella (Walker) (Lepidoptera: Phycitidae) larvae treated with Bacillus thuringiensis var. kurstaki. - Univ. J. Zool. Rajshahi Univ. 12: 73-79.

Furaki S.I., Das D.R., Khan A.R. \& Khatun M. 2007: Effects of ultraviolet $(254 \mathrm{~nm})$ irradiation on egg hatching and adult emergence of the flour beetles, Tribolium castaneum, T. confusum and the almond moth, Cadra cautella. - J. Insect Sci. 7: $1-6$.

Ghanem I. \& Shamma M. 2007: Effect of non-ionizing radiation (UVC) on the development of Trogoderma granarium Everts. - J. Stor. Prod. Res. 43: 362-366.

Guedes R.N.C., Zhu K.Y., Opit G.P. \& Throne J.E. 2008: Differential heat shock tolerance and expression of heat-inducible proteins in two stored-product psocids. - J. Econ. Entomol. 101: 1974-1982.
Halverson S.L., Phillips T.W., Bigelow T.S., Mbata G.N. \& PAYTON M.E. 1999: The control of various species of storedproduct insects with EHF energy. In Proceeding of the Annual International Research Conference on Methyl Bromide Alternatives and Emissions Reductions. San Diego, CA, November 1, 1999. $4 \mathrm{pp}$

HasAn M. \& KHAn A.R. 1998: Control of stored-product pests by irradiation. - Integr. Pest Manag. Rev. 3: 15-29.

HuANG L.H. \& KANG L. 2007: Cloning and interspecific altered expression of heat shock protein genes in two leafminer species in response to thermal stress. - Insect Mol. Biol. 16: 491-500.

LAH E.F., Musa R.N. \& Ming H.T. 2012: Effect of germicidal UV-C light $(254 \mathrm{~nm})$ on eggs and adult of house dustmites, Dermatophagoides pteronyssinus and Dermatophagoides farina (Astigmata: Pyroglyhidae). - Asian Pac. J. Trop. Biomed. 2: 679-683.

Lee H.J., Lee Y.J., Kwon H.C., Bae S., Kim S.H., Min J.J., Cho C.K. \& LeE T.S. 2006: Radioprotective effect of heat shock protein 25 on submandibular glands of rats. - Am. J. Pathol. 169: $1601-1611$.

Livak K.J. \& Schmittgen T.D. 2001: Analysis of relative gene expression data using real-time quantitative PCR and the $2^{-\Delta \Delta \mathrm{Ct}}$ method. - Methods 25: 402-408.

Lu H.H., Zhou J.C., Xiong S.B. \& Zhao S.M. 2010: Effects of low-intensity microwave radiation on Tribolium castaneum physiological and biochemical characteristics and survival. J. Insect Physiol. 56: 1356-1361.

Lu H.H., Zhou J.C., Zhaо S.M. \& Xiong S.B. 2011: Effects of microwave radiation on conductive heating on Tribolium castaneum microstructure. - Micron 42: 36-41.

Mahroof R., Subramanyam B., Throne J.E. \& Menon A. 2003: Time-mortality relationships for Tribolium castaneum (Coleoptera: Tenebrionidae) life stages exposed to elevated temperatures. - J. Econ. Entomol. 96: 1345-1351.

Mahroof R., Zhu K.Y. \& Subramanyam B. 2005: Changes in expression of heat shock proteins in Tribolium castaneum (Coleoptera: Tenebrionidae) in relation to developmental stage, exposure time, and temperature. - Ann. Entomol. Soc. Am. 98: $100-107$.

McCloud E.S. \& Berenbaum M. 1999: Effects of enhanced UV-B radiation on a weedy forb (Plantago lanceolata) and its interations with a generalist and specialist herbivore. - Entomol. Exp. Appl. 93: 233-247.

Nguyen T.T.A., Michaud D. \& Cloutier C. 2009: A proteomic analysis of the aphid Macrosiphum euphorbiae under heat and radiation stress. - Insect Biochem. Mol. Biol. 39: 20-30.

Noomhorm A., Sirisoontaralak P., Uraicheun J. \& Ahmad I. 2009: Effects of pressurized carbon dioxide on controlling Sitophilus zeamais (Coleoptera: Curculionidae) and the quality of the milled rice. - J. Stor. Prod. Res. 45: 201-205.

Pattison D. \& Davies M. 2006: Actions of ultraviolet light on cellular structures. In Bignold L.P. (ed.): Cancer: Cell Structures, Carcinogens and Genomic Instability. Birkhäuser, Basel pp. 131-157.

Sang W., Ma W.H., Qiu L., Zhu Z.H. \& Lei C.L. 2012: The involvement of heat shock protein and cytochrome P450 genes in response to UV-A exposure in the beetle Tribolium castaneum. - J. Insect Physiol. 58: 830-836.

Shallom J.M., Di Carlo A.L., Ko D., Penafiel L.M., NaKai A. \& Litovitz T.A. 2002: Microwave exposure induces Hsp70 and confers protection against hypoxia in chick embryos. $-J$. Cell Biochem. 86: 490-496.

Sharma M.K. \& Dwivedi S.C. 1997: Investigation on the effects of ultraviolet and infra-red light on the life cycle of Callosobruchus chinensis Linn. - J. Adv. Zool. 18: 27-31. 
STOREY C.L. 1987: Effect and control of insects affecting corn quality. In Watson S.A. \& Ramstad P.E. (eds): Corn Chemistry and Technology. American Association of Cereal Chemists, St. Paul, pp. 185-199.

Tammariello S.P., Rinehart J.P. \& Denlinger D.L. 1999: Dessication elicits heat shock protein transcription in the flesh fly, Sarcophaga crassipalpis, but does not enhance tolerance to high or low temperature. - J. Insect Physiol. 45: 933-938.

Tilton E.W. \& Brower J.H. 1983: Radiation effects on arthropods. In Josephson E.S. \& Peterson M.S. (eds): Preservation of Food by Ionizing Radiation. Vol. 2. CRC Press, Boca Raton, FL, pp. 269-316.

Tungutimitayakul J., Tatun N., Vajarasathira B. \& Sakurai S 2015: Expression of heat shock protein genes in different developmental stages and after temperature stress in the maize weevil (Coleoptera: Curculionidae). - J. Econ. Entomol. 108: 1313-1323.

Vadivambal R., JaYAS D.S. \& White N.D.G. 2008: Determination of mortality of different life stages of Tribolium castaneum (Coleoptera: Tenebrionidae) in stored barley using microwaves. - J. Econ. Entomol. 101: 1011-1021.
Vadivambal R., DejI O.F., Japas D.S. \& White N.D.G. 2010: Disinfestation of stored corn using microwave energy. - Agric. Biol. J. North Am. 1: 18-26.

Valizadegan O., Pourmirza A.A. \& Safaralizadeh M.H. 2009: Combination of microwave radiation and cold storage for control of Oryzalephilus surinamensis (L.) (Col. Silvanidae). - J. Biol. Sci. 9: 231-236.

Yu H., WAN F. \& GuO J. 2012: cDNA cloning of heat shock protein genes and their expression in an indigenous cryptic species of the whitefly Bemisia tabaci complex from China. - J. Integr. Agric. 11: 293-302.

Webber M.M., Barnes F.S., Seltzer L.A., Bouldin T.R. \& PraSAD K.N. 1980: Short microwave pulses cause ultrastructural membrane damage in neuroblastoma cells. - J. Ultrastruct. Res. 71: 321-330.

Zhang Y., Liu Y., Guo X., Li Y., Gao H., Guo X. \& Xu B. 2014: sHsp22.6, an intronless small heat shock protein gene, is involved in stress defence and development in Apis cerana cerana. _ Insect Biochem. Mol. Biol. 53: 1-12.

Zhao S., Qiu C., Xiong S. \& Cheng X. 2007: A thermal lethal model of rice weevils subjected to microwave irradiation. $-J$. Stor. Prod. Res. 43: 430-434.

Received October 21, 2015; revised and accepted December 3, 2015 Published online January 28, 2016 